\title{
Relative Rewards within Team-Based Compensation
}

\author{
BERND IRLENBUSCH and GABRIELE K. RUCHALA
}

December 2006

\begin{abstract}
How to design compensation schemes to motivate team members appears to be one of the most challenging problems in the economic analysis of labour provision. We shed light on this issue by experimentally investigating team-based compensations with and without bonuses awarded to the highest contributors in teams. A purely team-based compensation scheme induces agents to voluntarily cooperate while introducing an additional relative reward increases effort and efficiency only when the bonus is substantial. In this case, however, the data suggests that tournament competition crowds out voluntary cooperation within a team.
\end{abstract}

\section{Keywords}

Teamwork; Bonus Pools; Relative Rewards; Motivation Crowding Out; Voluntary Cooperation; Personnel Economics; Experiments

\section{JEL Classification Codes}

C72; C91; H41; J33; L23; M52

\section{Authors}

Bernd Irlenbusch

London School of Economics

Department of Management (MES)

Houghton Street

London WC2A 2AE

United Kingdom

tel: $+44-20-7955-7840$

fax: +44-20-7955-6887

Gabriele Ruchala

University College London

Department of Economics (ELSE)

Gower Street

London WC1E 6BT

United Kingdom

tel: +44-20-7679-5852

fax: +44-20-7916-2774

e-mail: b.irlenbusch@1se.ac.uk

e-mail: g.ruchala@ucl.ac.uk

We thank two anonymous referees, David Dickinson, Andrea Ichino, Manfred Königstein, and Dirk Sliwka for very helpful comments to improve the paper. All errors are our own. Financial support by the Deutsche Forschungsgemeinschaft (through grants IR43/1-1, KR2077/2-1 and KR2077/2-3) and by the Economic and Social Research Council (via ELSE) is gratefully acknowledged. 


\section{Introduction}

Teamwork is increasingly seen as an appropriate structure to organise various labour environments (Beyerlein 2000, Mueller, Procter, and Buchanan 2000, Prat 2002, Zwick 2004, van Hootegem, Benders, Delarue, and Procter 2005). The suitable provision of incentives for teams, however, appears to be one of the most challenging tasks in labour economics (Main, O’Reilly, and Wade 1993, DeMatteo, Eby, and Sundstrom 1998, HAMILTON, NiCKERSON, and OWAN 2003). In general wage contracts of teams are not conditioned on individual contributions (as it is the case in piece rate contracts) because contributions can neither be (easily) disentangled nor verified before a court. This is one of the reasons why team members are often rewarded according to the output of the team as a whole. Another purpose is to encourage cooperative behaviour in the sense that individual team members strive for the best outcome of the whole team. From a strategic point of view, however, such a scheme provides considerable free-riding incentives, which might lead to inefficient effort levels (see, for example, Alchian and DemSETZ 1972, Newhouse 1973, HOLMSTRÖM 1982, HANSEN 1997).

An intuitive approach to reduce the severity of free-riding incentives in teams is to promise relative rewards to the best individual performers in the team (HENEMAN and VON HIPPEL 1995). In practice relative rewards within teams often take the form of bonuses ${ }^{1}$ (for example, for the "employee of the month") or promotions which imply higher salaries. One reason why relative rewards are so popular stems from the fact that output needs only to be measured relatively which constitutes a big advantage when absolutely measuring individual outputs is prohibitively costly. Even if the individual contributions of team members are not verifiable to a third party, the employer can commit himself to a relative incentive scheme. The commitment is credible as long as the individual (relative) outputs are observable (for example by the team leader) and the act of actually transferring the ex-ante promised relative

\footnotetext{
1 The total amount of the bonuses usually varies with the size of the bonus pool which is determined by some objective measures like overall corporate profit. How the bonuses are exactly awarded among the team members is rarely contracted explicitly and is often determined subjectively, for example, by more or less objective appraisals assessed by a team leader (RAJAN and REICHELSTEIN 2006). Team leaders are encouraged to sufficiently differentiate their ratings by making use of the full range of grades (MURPHY 1992). These so called forced rankings can be directly related to bonus pay systems, to decisions on promotions, or even to advising low performers to leave the company (PFEFFER and SUTTON 1999).
} 
rewards is verifiable (for example, before a court). ${ }^{2}$ Relative reward schemes that induce competition among team members for positions in a ranking are also referred to as tournaments (LAZEAR and ROSEN 1981). Why might an additional tournament structure alleviate the free-rider problem in teams? The idea is that the additional competition for rewards between team members induces them to exert more effort which would align the individual interests with the responsibility for the common good. We aim at contributing to the understanding of how compensation schemes affect human behaviour by providing a clear-cut comparison of a hybrid pay scheme to its components. We concentrate on the strategic and behavioural aspects of team-based compensation schemes with and without a relative reward by investigating them in a game-theoretic model and in an abstract non-real effort experiment. By doing so we provide evidence that additional individual rewards in teams are likely to crowd out voluntary cooperation. To the best of our knowledge a crowding out effect for the highly realistic compensation package composed of tournament incentives and team incentives has not been documented before in the literature.

Laboratory experiments have the decisive advantage that one can compare behaviour under different clear-cut conditions without distorting effects which are normally present when collecting data from the field. Thus, experiments appear to be a valuable complementary source of insight (in addition to theory and field studies) in order to gain a more complete picture regarding the behavioural consequences of reward schemes (FALK and FEHR 2003). In addition to a purely team-based compensation treatment we consider two treatments in which the team incentive is supplemented by a relative reward - a low and a high bonus, respectively. As a benchmark we also look at a pure bonus situation without a team component. A team-based compensation with a relative reward is modelled such that it is selffunded by letting the agents finance the additional bonus (in equal shares). This guarantees that the wage costs for the employer are the same under the different remuneration schemes (provided that the total amount of effort is the same).

Our results indicate that average effort and efficiency increase significantly only if the bonus is high. A low bonus does not have a noticeable influence on effort or efficiency. Moreover, only in the absence of a relative reward (i.e., only with the purely team-based compensation) significant over-contributions (compared to the equilibrium effort level) are observed which

\footnotetext{
2 Note that the non-verifiability of the individual contributions to a third party does not induce a moral hazard problem on the side of the employer (as would be the case with piece rates) as long as the actual act of awarding
} 
decline over time. Interestingly, in the team-based compensation scheme with the high bonus average effort is quite stable over rounds with almost non-existing over-contributions right from the beginning. Why do over-contributions vanish in the presence of a high relative reward? One reason could be that pure tournament incentives induce effort levels below the equilibrium prediction. If this is true over-contributions and under-contributions would simply cancel out in the hybrid compensation scheme. However, in our pure bonus benchmark treatment actually observed effort levels fit the equilibrium prediction quite well if at all, we only find evidence in the direction of over-contributions. Thus, our data suggest that the competition induced by an additional individual relative reward seems to destroy the cooperative attitude of team members and, in this sense, crowds out motivation to exert effort above individually rational levels. From a strategic, behavioural point of view it seems that a pure team reward enables team members to see the necessity for cooperation more clearly. The promise of an individual relative reward tempts team members to focus on obtaining the bonus and, thereby, seems to distract them from potential gains of voluntary cooperation.

Some studies conducted in natural environments already suggest that one should be careful when combining group compensation and individual rewards. ROSENBAUM et al. (1980), for example, find that groups performed relatively poorly when hybrid rewards (i.e., group-based rewards augmented by individual rewards) rather than pure group rewards were given for performance on highly independent tasks. They concluded that even a small proportion of individual rewards undermines performance of a group task. A study by WAGEMAN (1995) points into a similar direction. She argues that the introduction of group level rewards in addition to individual pay weakens worker's sense of individual responsibility, without providing strong enough collective motivation.

It has also been observed that additional extrinsic incentives (provided for example by rewards or punishment) do not necessarily lead to an increase but can even reduce effort. The detailed mechanisms that drive such crowding out effects, as they are termed by FREY (1997), still constitute a largely unresolved puzzle. Evidence in favour of crowding out effects has been provided by GNEEZY and RUSTICHINI (2000a, b). By conducting imaginative field experiments they show, for example, that students who individually collect donations for charity programs perform better when they receive no monetary reward at all compared to those who are paid a small bonus proportional to the amount they collect. To some extent 
these observations can be explained by an approach proposed by psychologists, according to which an activity can have a motivation of its own, called intrinsic motivation. They argue that intrinsic motivation may be diminished by extrinsic incentives such as performance contingent monetary rewards. ${ }^{3}$ Our setting is designed to deliberately eliminate the effect of intrinsic motivation which might emerge from an (enjoyable) real effort task. By representing effort through the choice of abstract numbers we concentrate on an additional, important aspect of motivation crowding out, which is constituted by the purely strategic aspect of crowding out of voluntary cooperation, without allowing for intrinsic motivation.

FEHR and ROCKENBACH (2003) show that the performance of agents in an abstract, non-real effort task is considerably reduced if a principal chooses incentives in the form of a punishment scheme. An analogous but weaker effect of performance crowding out is reported in FEHR and GÄCHTER (2002). They find that even the promise of a performance contingent reward of a fixed size may undermine voluntary effort contributions. ${ }^{4}$ GNEEZY and RUSTICHINI (2000a), GNEEZY (2005), and MANTHEI (2006) report evidence that extrinsic incentives influence effort in a non-monotonic way: While relatively small monetary incentives bear the potential to crowd out motivation, relatively large incentives increase effort at least as long as the resulting wages are below a certain reference level. All these studies look at work environments for individuals without considering team settings.

In line with other experimental studies on team compensation schemes (for example, NALBANTIAN and SCHOTTER 1997, CROSON 2001, SutTER 2006) we focus on a strategic setting similar to a voluntary contribution mechanism for public goods (for overviews see DAvis and Holt 1993, Ledyard 1995, and CAMERER 2003). Similar to public goods situations our team members equally share the group output. However, there are also some differences: In our team compensation scheme it appears to be more suitable to implement a convex and increasing cost function for effort which leads to an interior equilibrium solution (normally supply functions with constant marginal costs are considered in public goods which

not rewarding the (subjectively) identified top performers.

3 Crowding out of intrinsic motivation by extrinsic rewards is discussed, for example, in DECI (1971), LEPPER, GreENE, and Nisbett (1973), DeCi, KoESTNER, and RyAn (1999). For an overview on experimental studies see for instance PITTMANN and Heller (1987), WIERSMA (1992), and TANG and HALl (1995). The argument, however, that extrinsic motivation crowds out intrinsic motivation is not undisputed among psychologists, see, for example, CAMERON and PIERCE (1994) and EISENBERGER and CAMERON (1996).

4 For similar results see Frey and OBERHOlzER-GeE (1997), BOHNET, Frey, and HuCK (2001), FreY and JEGEN (2001), FEHR and FALK (2002), FEHR and List (2004), GÄCHTER, KESSLER, and KÖNIGSTEIN (2005), FALK and Kosfeld (2006), FeHR, KLEIN, and SCHMIDT (2006). For an overview of the literature on crowdingout see BowLES (2005). 
result in a corner solution as an equilibrium). Additionally, in our setting output in teams is determined not only by effort but also by a stochastic influence, which represents luck or (subjective) measurement uncertainties of individual contributions. One general finding in the public goods literature is that in repeated settings individuals cooperate to a high extent above the equilibrium especially in the beginning of an interaction while cooperation diminishes over time. This effect was initially observed in linear public goods games (for example IsAAC, WALKER, and THOMAS 1984) in which the equilibrium effort (no contribution) and the efficient effort (full contribution) are both corner solutions. The two most prominent arguments for the decay in contributions are: $(i)$ participants learn to free-ride over rounds and (ii) participants play history-dependent strategies which lead both conditional cooperators and free riders to decrease their contributions over time. Although some studies report hints that the learning explanation cannot be completely rejected, a majority provides evidence in support of a more pronounced effect of the "strategies" explanation." Muller, SEFTON, STEINBERG, and VESTERLUND (2006), for example, report a clever designed experiment: They analyse two public goods games which are consecutively played by the same participants by eliciting complete strategies. This two-stage game is repeated five times always with a new matching such that no participant is ever matched with another participant more than once. They find that on average, stage two contributions are 45\% lower than stage-one contributions while the stage-one contributions decrease only by on average $7 \%$ in each repetition. In line with this evidence in favour of the "strategies" explanation, initially high contribution levels and a subsequent decay are also the rule in non-linear public goods games with an interior equilibrium as we have in our setting (KESER 1996, SEFTON and STEINBERG 1996, and NALBANTIAN and SCHOTTER 1997).

A second category of experimental work which is related to our study is constituted by experimental studies on tournament incentive schemes (see for example BULL, SCHOTTER, and Weigelt 1987, VAn DiJK, Sonnemans, and VAN Winden 2001, Harbring and Irlenbusch 2003, OrRison, SchotTer, and Weigelt 2004, Harbring and Irlenbusch

\footnotetext{
5 ISAAC, WALKER, and THOMAS (1984) invite experienced participants back to the laboratory and find that behaviour of experienced and inexperienced subjects is basically the same. A similar restart effect is observed by CROSON (1996). ISAAC, WALKER, and WILLIAMS (1994) report evidence that the steady decay occurs also in longer public goods experiments and they suggest that the rate of decay is inversely related to the number of decision rounds. KESER (2000) elicits strategies for a repeated simultaneous-move public good game and finds that strategies typically consists of high initial contributions, followed by a phase of reciprocation, and then by a very pronounced endgame effect. ANDREONI (1995) shows that more than half of the initially high contributions to public goods must be intentional rather than "error". Partial indications in favour of the "learning"
} 
2005). Among other findings in general they confirm one of the central results from tournament theory: Effort increases in the size of the bonuses. None of these studies, however, deals with the integration of individual and group incentives.

The three experimental studies which are most akin to our analysis also investigate individual incentives as a way to increase effort among members of work teams. DICKINSON and ISAAC (1998) model the use of individual monetary rewards in team production with workers of different abilities by conducting conventional public goods games with heterogeneously endowed agents. They introduce bonuses for high absolute contribution levels and bonuses for high relative (to endowment/ability) contribution levels. Absolute and also relative rewards significantly increase contributions to the public goods compared to a situation without any bonus. Furthermore, they find that the increase is larger if relative rather than absolute bonuses are paid. DICKINSON (2001) extends the former study by additionally analyzing negative incentives in the form of penalties. Bonuses (carrots) and penalties (sticks) are awarded based on absolute or relative (to endowment/ability) contributions. He finds that not only bonuses but also penalties increase contributions which are highest if the relative to endowment measure is used. If the absolute measure is used penalties seem to induce higher contributions than bonuses. SUTTER (2006) investigates team compensation schemes in the form of threshold public goods games. In his innovative extension team members compete for higher remuneration in the form of high contributors "earning" the role of an early proposer in an alternating-offer bargaining process. Hereby the tournament prizes can be endogenously determined by the team members which nicely resembles the situation of self-managed teams. All three studies mentioned constitute interesting starting points in the experimental analysis of the combination of individual and group incentives. Our approach is different as we compare the impact of two standard compensation schemes (team compensation and relative rewards) to their combined effect by integrating the labour tournament model suggested by LAZEAR and ROSEN (1981) into an adapted voluntary contribution mechanism.

The paper is structured as follows: In section 2 we introduce a simple model of team-based compensation with a bonus and derive a game theoretic equilibrium benchmark. In section 3 our hypotheses are presented. These are followed by the experimental design and procedures in section 4. The experimental results are summarised in section 5 while section 6 contains an

explanation can be found in ANDREONI (1988), ANDREONI (1995), PALFREY and PRISBEY (1996), and HoUSER and KURZBAN (2002). 
additional comparison with a pure bonus compensation scheme. Section 7 concludes by discussing practical implications and pointing at interesting extensions and further research.

\section{A Simple Model of Team-Based Compensation with Bonus}

This section presents a simple model on relative rewards within team-based compensation. Additionally its game theoretic analysis is described to provide a benchmark of behaviour.

We consider a set of agents $i(i=1, \ldots, n)$ who simultaneously choose their effort levels $e_{i}$ out of the interval $[0, \bar{e}]$ (with a fixed length of $\bar{e}$ ). The output $y_{i}$ of agent $i$ is determined by the following production function

$$
y_{i}=e_{i}+\varepsilon_{i}
$$

with $\varepsilon_{i}$ as a random variable which is uniformly distributed over the interval $[-\bar{\varepsilon},+\bar{\varepsilon}]$ (symmetric around zero with a fixed constant length of $2 \bar{\varepsilon}$ ) and assumed to be i.i.d. for all agents. ${ }^{6}$ The random component represents a measurement uncertainty (possibly due to the subjectivity of the team leader) with regard to effort or a true randomness in the production technology. In our baseline setting we analyse an adapted voluntary contribution mechanism. This mechanism resembles a purely team-based compensation scheme: the benefit from the total output of the whole team is equally distributed between its members while each agent $i$ individually has to bear the cost of effort resulting from his own effort choice $e_{i}$. Costs of effort $C\left(e_{i}\right)$ are identical for all agents (which basically means that they have the same ability) and are described by a convex function of the type $C\left(e_{i}\right)=e_{i}^{2} / \bar{c}$ with a fixed constant $\bar{c}$. The expected payoff function of each team member in the purely team-based compensation scheme is given by

$$
\Pi_{i}^{\text {pure_team }}=k \sum_{j=1}^{n}\left(e_{j}+\varepsilon_{j}\right)-C\left(e_{i}\right)
$$

where $k>0$ denotes the marginal per capita return and $n$ denotes the number of members in the team.

\footnotetext{
${ }^{6}$ To keep the experimental design tractable we assume that the tasks of the team members are independent, i.e., the productivity of one team member $i$ is not affected by the effort of another team member $j:\left(\partial^{2} \Pi / \partial e_{i} \partial e_{j}\right)=0$ with $\Pi$ denoting the total team output and $e_{i}$ and $e_{j}$ the effort choices of two team members $i$ and $j$ respectively. This assumption is usually applied in experimental studies on teamwork (NALBANTIAN and SCHOTTER 1997, CROSON 2001, SUTTER 2006).
} 
In a second setting we supplement the team compensation with a bonus $\Delta$ which is promised to the (subjectively determined) highest contributor in the team. Thus, the bonus payment depends exclusively on the relative output position between the team members. In order to ensure comparability we keep the wage sum for a given total effort level identical in the two settings. This is done by financing the relative reward by a constant fee $\Delta / n$ which is collected from each agent. Thus, the expected payoff function of team member $i$ in the teambased compensation scheme with a bonus is given by

$$
\Pi_{i}^{\text {bonus_team }}=k \sum_{j=1}^{n}\left(e_{j}+\varepsilon_{j}\right)+\varphi_{i}\left(e_{1}, \ldots, e_{n}\right) \Delta-C\left(e_{i}\right)-\frac{\Delta}{n}
$$

with $\varphi_{i}\left(e_{1}, \ldots, e_{n}\right)$ denoting the probability for agent $i$ to win the relative reward $\Delta$. Note that for each symmetric effort combination the expected payoff of an agent does not differ between both settings. The agent who contributes most is most likely to win an additional prize; the other agents in the team receive no additional payment. Thus, the integrated relative incentive scheme can be interpreted as an $n$-player rank-order tournament with a winner prize of $\Delta$ and $(n-1)$ loser prizes of 0 .

In the following we derive a benchmark for behaviour from a game-theoretic analysis while assuming for simplicity that agents are risk neutral and aim to maximise their monetary payoffs. To determine the Nash equilibrium solution for the baseline setting, we have to consider the first-order condition:

$$
k=\frac{2 e_{i}}{\bar{c}}
$$

Thus, we obtain the following equilibrium effort in the purely team-based compensation scheme:

$$
e_{\text {pure } \_ \text {team }}^{*}=\frac{k \bar{c}}{2}
$$

Note that our setting is different from a linear voluntary contribution mechanism (which is usually considered in the experimental literature) since both the equilibrium contributions and the efficient contributions are non-corner solutions in the action space for sufficiently large 
$\bar{e}$ (for related settings see KESER 1996 or NALBANTIAN and SchOTTER 1997). In the bonus setting the following first-order condition has to hold: ${ }^{7}$

$$
k+\frac{\partial \varphi_{i}\left(e_{1}, \ldots, e_{n}\right)}{\partial e_{i}} \Delta=\frac{2 e_{i}}{\bar{c}}
$$

One can show that under the assumption of uniformly distributed random components in the production function the marginal probability of winning the reward depends only on the size of the interval from which the random components are drawn ${ }^{8}$ :

$$
\frac{\partial \varphi_{i}\left(e_{1}, \ldots, e_{n}\right)}{\partial e_{i}}=\frac{1}{2 \bar{\varepsilon}}
$$

This results in the following equilibrium effort exerted in the bonus setting:

$$
e_{\text {bonus_team }}^{*}=\frac{k \bar{c}}{2}+\frac{\bar{c} \Delta}{4 \bar{\varepsilon}}
$$

Thus, the equilibrium effort in the bonus setting is determined by two additive components: the equilibrium effort played in the purely team-based compensation setting increased by a component dependent on the size of the bonus $\Delta .{ }^{9}$

A second benchmark for behaviour is provided by the effort which maximises efficiency understood as the total payoff for all agents:

$$
e_{\text {pure_team }}^{\text {eff }}=e_{\text {bonus_team }}^{\text {eff }}=\frac{n k \bar{c}}{2}
$$

Since the additional reward in the bonus setting is financed by the agents themselves, the efficient effort level is identical in both reward settings.

\section{Hypotheses}

Our aim is to analyse the effectiveness of a relative reward as a supplementing incentive device in a team-based compensation scheme. The theoretical analysis shows that ceteris

\footnotetext{
${ }^{7}$ The existence of a (symmetric) Nash equilibrium is guaranteed if the participation constraint is fulfilled. In our setting this means that the expected payoff of an agent in equilibrium is larger than zero. For the parameters chosen in our experiment (see below) the participation constraints are satisfied in all treatments.

${ }^{8}$ For the exact calculation of the marginal probability of winning see HARBRING and IRLENBUSCH (2005).

${ }^{9}$ The second summand (dependent on the bonus $\Delta$ ) constitutes the symmetric equilibrium solution in a pure tournament which is derived later on in the paper.
} 
paribus the combination of a relative reward together with a team-based compensation raises effort which implies that the equilibrium effort in the purely team-based compensation scheme should be lower than the equilibrium effort in the bonus team-based compensation scheme.

\section{Hypothesis "Effort":}

Team-based compensation with a relative reward yields higher effort than the purely team-based compensation.

Note that it is not only individually rational to increase effort but also desirable from the perspective of the team as a whole because each team member benefits from higher output. Thus, due to the higher equilibrium effort in the team-based compensation with a relative reward the presence of a bonus should also raise efficiency, i.e., efficiency in the purely teambased compensation scheme should be lower than the efficiency in the bonus team-based scheme. $^{10}$

\section{Hypothesis "Efficiency":}

Team-based compensation with a relative reward generates higher efficiency than the purely team-based compensation.

If the stage game is repeated a finite number of times within the same group the subgame perfect equilibrium effort in each repetition is equal to the effort obtained in the stage game. Thus, according to the theoretical analysis we should not observe a change in effort over time. This is true for the purely team-based compensation scheme and the bonus team-based compensation scheme. In many experiments on voluntary contribution games, however, one observes high cooperative behaviour (in terms of contributions above the Nash equilibrium) in the beginning which declines over time until it reaches the Nash equilibrium solution of the stage game. Thus, our third hypothesis deals with the development of effort over time.

\footnotetext{
${ }^{10}$ In the (symmetric) equilibrium this is true if the incentives to exert higher effort (and thus the costs for the additional effort) are not tremendously high, i.e., if $\Pi_{i}^{\text {bonus_team }}\left(e^{*}\right.$ bonus_team $)>\Pi_{i}^{\text {pure_team }}\left(e^{*}\right.$ pure_team $) \Leftrightarrow$ $\Delta<4(n-1) k \bar{\varepsilon}$. Given the parameter values in our experiment this condition is satisfied. Note that even if average effort is higher in the treatment with a relative reward than in the one with purely team-based compensation, efficiency can well be lower in the former than in the latter (due to a higher variance of individual effort levels which is often observed in tournaments; see for example, BuLL et al. (1987), VAN DIJK et al. (2001), HARBRING and IRLENBUSCH (2003)).
} 


\section{Hypothesis "Trend": \\ Effort decreases over time in both team-based compensation schemes and approaches equilibrium behaviour.}

While we expect cooperatively high contribution levels in the beginning under both teambased compensation schemes we do not assume that contributions are significantly higher than equilibrium behaviour in the end.

Since the bonus is endogenously financed by the agents, the wage sum for a given total effort level is equal in both compensation schemes. This fact might already cast some doubts on the expectation that effort is increased by the bonus. Additionally as mentioned above there exists steadily growing evidence from various disciplines that motivation might be crowded out if explicit incentives like relative rewards are provided (for example FREY 1997, HEATH 1999, FeHr and GÄCHTER 2000, FeHr and Rockenbach 2003, IRLENBUSCH and SliWKa 2006). A natural way to measure motivation for exerting effort voluntarily (to the benefit of the whole team) is to look at over-contributions in the sense of how much effort team members are willing to contribute above the individual rational level.

\section{Hypothesis “Crowding Out of Voluntary Cooperation”:}

A higher bonus in a team-based compensation reduces over-contributions compared to the equilibrium effort.

Note that if our hypothesis is confirmed our study adds evidence to the literature that motivation for voluntary contribution might be crowded out by extrinsic incentives in a purely strategic, behavioural sense without drawing on crowding out of intrinsic motivation. Given that our setting is highly realistic for compensation packages in real organisations, it is quite surprising that, to the best of our knowledge, this kind of evidence does not exist for teambased compensation schemes which are supplemented by individual relative rewards. From a theoretical point of view additional relative rewards should unambiguously increase (extrinsic) motivation. Thus, there might be a trade-off between increasing and decreasing effort when supplementing team-based compensations with a tournament structure.

\section{Experimental Design}

For a clear-cut investigation into the influence of relative rewards within team-based compensation on the motivation to exert effort we compare team-based compensation 
schemes without and with a relative reward. The bonus is promised to the highest contributor. Note that the bonus is self-funded and leaves the total wage sum constant across treatments for a given effort level combination. We consider teams of $n=4$ agents who have to decide on their effort levels simultaneously. Each subject $i$ chooses an effort level $e_{i}$ out of the integer set $e_{i} \in\{0, \ldots, 120\}$. The random components $\varepsilon_{i}$ are independently and uniformly distributed over the integer interval $[-60,+60]$. The experimental design includes three treatments: Pure team denotes the treatment with a purely team-based compensation scheme, i.e., without a relative reward for the highest contributor in the team, while low bonus team and high bonus team denote treatments in which the team compensation is supplemented by a tournament bonus, i.e., by a relative reward for the highest contributor in the team. The latter two differ in their magnitude of the relative reward. While in low bonus team only a small bonus is awarded, the bonus is much larger in high bonus team. The design of the experiment is summarised in Table 1 which also shows the equilibrium efforts for each treatment.

Table 1: Design of the experiment

\begin{tabular}{lccc}
\hline \hline & \multicolumn{3}{c}{ treatments } \\
& pure team & low bonus team & high bonus team \\
\cline { 2 - 4 } Design & 30 & 30 & 30 \\
\# rounds & 48 & 48 & 48 \\
\# participants & 12 & 12 & 12 \\
\# independent observations & 0.5 & 0.5 & 0.5 \\
Parameters & 0 & 12 & 60 \\
marginal per capita return $k$ & $-60,+60]$ & {$[-60,+60]$} & {$[-60,+60]$} \\
relative reward $\Delta$ & $e^{2} / 100$ & $3+\left(e^{2} / 100\right)$ & $15+\left(e^{2} / 100\right)$ \\
random component interval & & & \\
cost of financing the bonus + & & & 50 \\
effort cost & 25 & 100 & 100 \\
Predictions & 100 & & \\
Nash equilibrium effort & & & \\
efficient effort & & & \\
\hline \hline
\end{tabular}

The computerised experiment was conducted in the Laboratorium für experimentelle Wirtschaftsforschung at the University of Erfurt. The experimental software was developed by making use of the toolbox z-Tree (FISCHBACHER 1999). In total 144 students of different disciplines participated in the experiment, with 24 subjects in each session and two sessions per treatment. Subjects were recruited by fliers as well as over the internet. Each subject was 
allowed to participate in one session only. Before starting the experiment the instructions ${ }^{11}$ were distributed and read to all participants. In order to avoid uncontrollable suggestive influences the language was kept neutral, i.e., expressions like "effort" and "wage" were avoided. Instead subjects, for example, had to choose a "number" and received a "payment". Cost tables were also handed out to the participants on which the costs induced by each number were listed. In the bonus team treatments a constant fee was directly included in the specified costs in order to finance the respective bonus. Thereafter, participants had to calculate examples to demonstrate their understanding of the game. ${ }^{12}$ Following this participants were randomly assigned to groups of four. The group composition was kept anonymous and constant during the experiment. Thus, we collected twelve independent observations for each treatment which are the basis for our statistical analysis. Subjects were not allowed to communicate other than via the experimental software. One session consisted of several rounds, i.e., 30 repetitions of the stage game.

In every round, subjects entered their chosen number representing their effort. The computer program drew the individual random numbers and calculated the payoffs of the four group members. After each round the following feedback was given to each subject: own effort choice, cost of own effort choice, total contribution of the group and own round payoff. Additionally, in the treatments with a relative reward participants learned whether they received the bonus or not. During the whole experiment subjects were shown their accumulated profits. ${ }^{13}$ No information was provided regarding the decisions of the other subjects in the group or the actual individual random numbers.

At the end of each session subjects were paid anonymously according to their performance. During the experiment subjects' payoffs were given in the fictitious experimental currency "taler" which in the end were changed into Euro by a previously known exchange rate of 180 talers per 1 Euro. On average each participant earned 10.40 Euro. Sessions lasted for about 90 minutes including instruction time.

\footnotetext{
11 Original instructions were written in German. They are available upon request from the authors. A translation is given in the Appendix.

12 The numbers and the random numbers for the examples were chosen by each participant herself before the introduction started. This procedure was used to keep possible suggestive influences as small as possible.

13 Participants received a starting capital of 300 talers in both treatments in order to cover potential losses. The starting capital accrued to their accumulated profits.
} 


\section{Experimental Results}

We start by analysing both compensation schemes separately with regard to effort, payoffs and changes in behaviour over rounds. Following this, the two schemes are compared with each other. Finally, the individual adjustment of effort choices over rounds is discussed.

\subsection{Behaviour under the purely team-based compensation scheme}

Table 2 shows the average effort exerted in each treatment aggregated over all 30 rounds. We find that the average effort in pure team lies significantly more often above than below the predicted equilibrium level (Binomial test, event probability $\alpha=0.5, p=0.000) .{ }^{14}$ Additionally, Figure 1 illustrates the average efforts over rounds per treatment. For clear graphical presentation results are pooled over five rounds. One can see that average effort in pure team is higher than theory predicts. On average over all players and rounds, we observe over-contributions of effort of almost 50 percent of the equilibrium contribution. Average effort, however, clearly declines over rounds and converges towards the equilibrium prediction.

Table 2: Overview of average results

\begin{tabular}{|c|c|c|c|c|c|}
\hline & average effort & $\begin{array}{l}\text { standard deviation of } \\
\text { effort over rounds }\end{array}$ & average payoff & average cost & $\begin{array}{l}\text { trend over } \\
\text { rounds }\end{array}$ \\
\hline pure team & $\begin{array}{l}37.04^{+++} \\
(25.00)\end{array}$ & 29.36 & $\begin{array}{c}49.73 \\
(43.75)\end{array}$ & $\begin{array}{c}22.34^{+++} \\
(6.25)\end{array}$ & $-0.3233^{* *}$ \\
\hline low bonus team & $\begin{array}{c}38.27 \\
(30.00)\end{array}$ & 27.76 & $\begin{array}{c}50.96 \\
(51.00)\end{array}$ & $\begin{array}{c}22.35^{+++} \\
(9.00)\end{array}$ & $-0.3525^{* *}$ \\
\hline \multirow[t]{2}{*}{ high bonus team } & $\begin{array}{c}53.12 \\
(50.00)\end{array}$ & 33.70 & $\begin{array}{c}68.55 \\
(75.00)\end{array}$ & $\begin{array}{l}39.57^{+++} \\
(25.00)\end{array}$ & -0.0735 \\
\hline & \multicolumn{5}{|c|}{ treatment differences } \\
\hline $\begin{array}{l}\text { pure team- } \\
\text { low bonus team }\end{array}$ & $p=0.356$ & $p=0.295$ & $p=0.421$ & $p=0.466$ & $p=0.378$ \\
\hline $\begin{array}{l}\text { pure team- } \\
\text { high bonus team }\end{array}$ & $p=0.000$ & $p=0.050$ & $p=0.001$ & $p=0.000$ & $p=0.030$ \\
\hline
\end{tabular}

Equilibrium values are given in parentheses. Standard deviation of effort over rounds is based on all individual single effort choices. The average cost excludes the cost for financing the bonus. The trend over rounds is indicated by the average Pearson correlation coefficient. Significance levels of treatment differences result from Mann-Whitney U-tests (one-tailed).

By using the Binomial test (one-tailed) we state the level of significance at which the null hypothesis can be rejected in favour of the alternative hypothesis that the average values are more often above the equilibrium level than below:

highly significantly above the equilibrium level: $\quad p \leq 0.01$

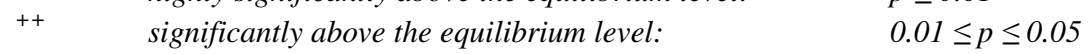

By using the Binomial test (one-tailed) we state the level of significance at which the null hypothesis can be rejected in favour of the alternative hypothesis that the Pearson correlation coefficient is more often negative than positive:

14 The average effort is determined for each observation. We use the Binomial test with an event probability of $\alpha=0.5$ to check whether values above the equilibrium are more frequent than when randomly drawn. 
Figure 1: Average effort over rounds

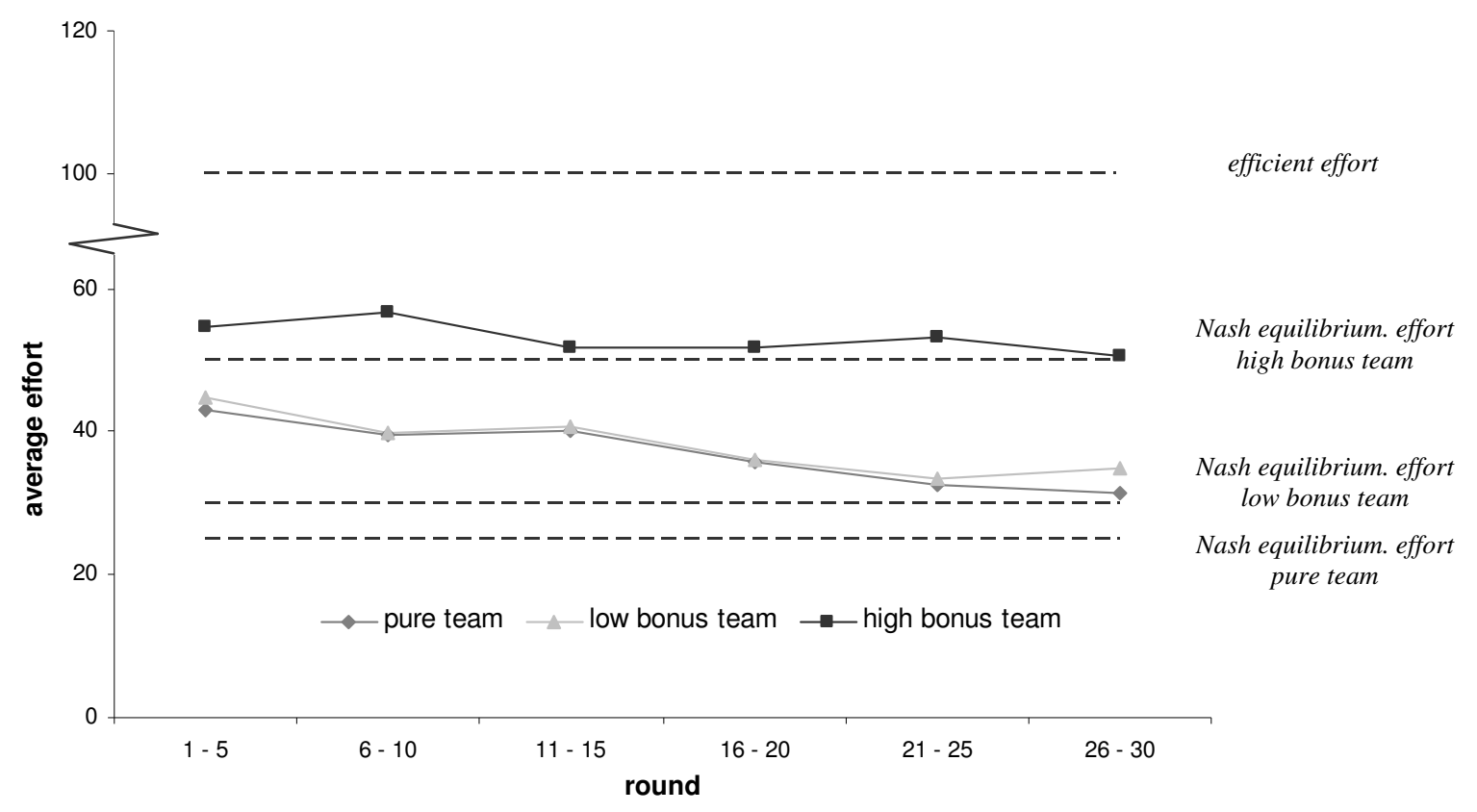

Data points are averages over five rounds.

In the treatment pure team it is a dominant strategy for each participant to choose an effort of 25 in each round. Figure 2 a shows the cumulative distribution of single effort choices per treatment. It can be seen that in the pure team treatment about 50 percent of effort choices are above the predicted equilibrium effort while in about 10 percent of the cases the exact equilibrium effort is chosen. In another 10 percent of all choices virtually no effort is exerted. Additionally, the cumulative distribution shows that almost the whole action space of possible effort choices is used, which means that effort levels range from 0 to 120 . However, effort levels above 80 appear to be quite rare. Prominent effort choices can be identified, as we observe jumps in the distribution particularly at multiples of ten. The highest peaks are observed at efforts of 25 and 50. Figure $2 \mathrm{~b}$ shows the cumulative distribution of average efforts exerted by individual subjects. It is evident that there is a high variance of average effort choices between subjects: Average effort levels primarily range from about 10 to 70 with slight peaks around 25, 35 and 45 . 
Figure 2a: Cumulative distribution of single effort choices

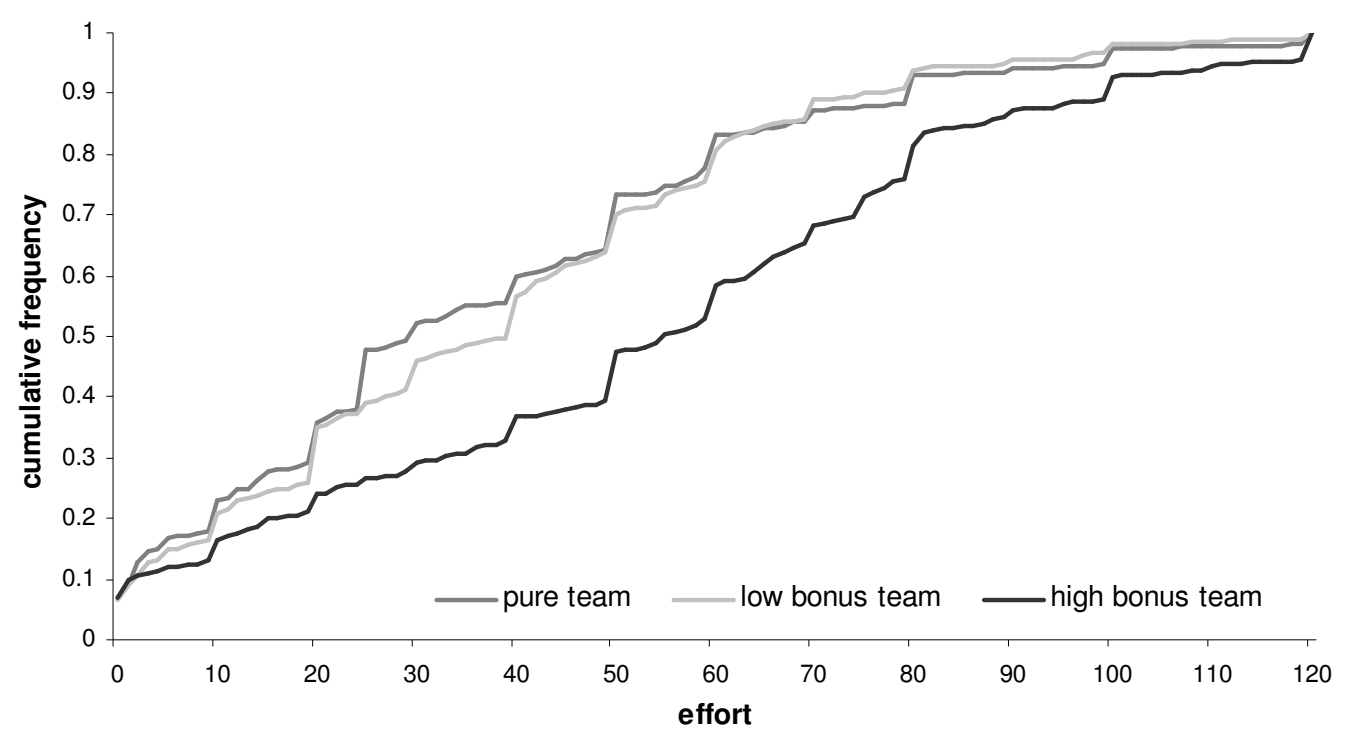

Figure 2b: Cumulative distribution of subjects' average effort choices

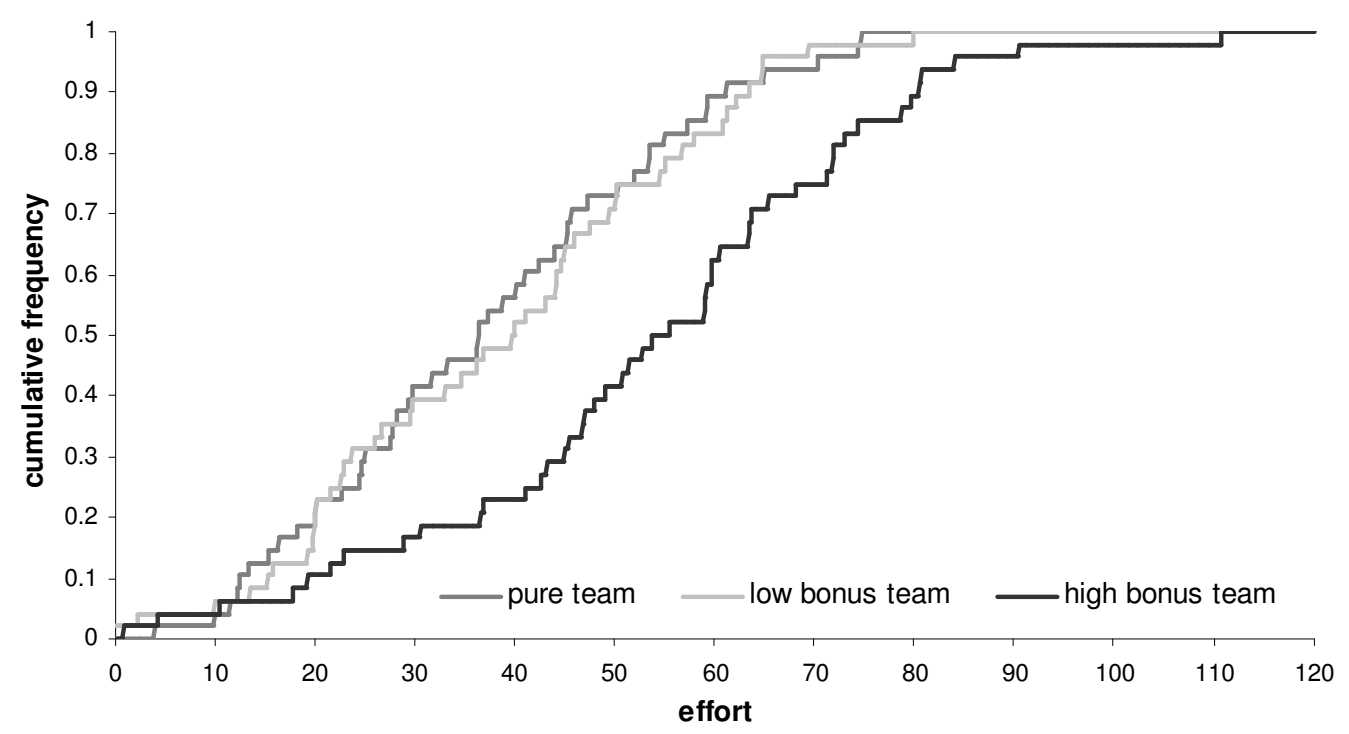

Since the average effort exerted is considerably higher than predicted by theory, it is not surprising that also the average costs of effort lie significantly more often above the equilibrium level than below (Binomial test, event probability $\alpha=0.5, p=0.0002$ ). However, it should be noted that the average cost of 22.34 (see Table 2) is much higher than the hypothetical cost for the observed average effort according to the effort cost function. Given this convex effort cost function this is due to the high variance of effort.

Under team-based compensation schemes it is the joint interest of the agents to establish high and stable effort levels. Even if each team member individually has an incentive to free-ride, that is to choose an effort level of only 25 , the team as a whole benefits from each effort unit 
exerted. This is true up to the Pareto optimal effort level of 100. Beyond, individual costs of an additional effort unit exceed the additional total benefit experienced by the team. If all agents choose the efficient effort level of 100, everybody earns 100 talers. Average payoffs per treatment are given in Table 2. We find that the average payoff in pure team is slightly higher than the theoretical predicted payoff in the Nash equilibrium, but this difference is not significant. Thus, subjects do hardly succeed in raising efficiency above the equilibrium level. Payoffs are quite stable over time in pure team.

It is interesting to have a look at the changes of behaviour over rounds. Visual inspection of the baseline treatment in Figure 1 already suggests the well known result from voluntary contribution mechanism experiments: Subjects start with a relatively high contribution but tend to lower their effort over time. To give this observation a statistical backing we calculated the Pearson correlation coefficient between round numbers and average contributions for each independent observation. The Binomial test shows that the Pearson correlation coefficients in pure team are significantly more often negative than positive (event probability $\alpha=0.5, p=0.0193$ ). Thus, we observe a falling trend of effort over rounds in the purely team-based compensation scheme.

\subsection{Behaviour under the bonus team-based compensation schemes}

In the treatment low bonus team, where we introduce a low relative reward for the highest contributor in the team, the average effort of 38.27 is above the predicted equilibrium effort of 30 (Table 2). This difference, however, is not significant at a conventional level. Figure 1 shows the average effort over rounds. We observe that average efforts of low bonus team and pure team run astonishingly parallel at the same level. Only in the last five rounds average effort in low bonus team seems to be slightly higher than in pure team. ${ }^{15}$ In the treatment high bonus team, where a high relative reward is introduced, the average effort of 53.12 comes quite close to the predicted equilibrium level of 50. In Figure 1 we observe that subjects already start with an average effort which is very close to the equilibrium prediction and stay at this effort level. Although, however, effort on average meets the equilibrium behaviour the inspection of the cumulative distribution of the treatment high bonus team in Figure 2a shows that almost the entire effort space is used. No effort is contributed in about 10 percent of all choices in low bonus team and high bonus team, respectively. Besides it becomes clear from

\footnotetext{
15 However, a pair-wise comparison of the average effort of the last five rounds yields no significance at a conventional level (Mann-Whitney U-test, $p=0.146$, one-tailed).
} 
Figure 2a that subjects again tend to prefer effort levels which are multiples of ten. Considerably many effort choices are made around 20 in low bonus team and around the equilibrium prediction of 50 in high bonus team. At these levels the highest increase in the distributions is located which is about 10 percent. From Figure $2 \mathrm{~b}$ a high variety of average effort choices between subjects in low bonus team and high bonus team respectively is evident. High peaks can be found at 20, 45 and 50 in the team-based compensation with the low bonus. In the team-based compensation with the high bonus high peaks can be found at 60, 70 and 80.

Although the average effort exerted is not significantly higher than predicted by theory in both bonus team-based compensation schemes, the average costs of effort lie significantly more often above the equilibrium level than below (Binomial test, event probability $\alpha=0.5$, low bonus team: $p=0.0002$; high bonus team: $p=0.0002$ ). Of course, this is again due to the high variance of effort in combination with the convex effort cost function.

We observe that the actual average payoff (50.96) in low bonus team corresponds quite well to the one predicted in the equilibrium (51.00). In high bonus team the actual average payoff (68.52) is lower than the theoretically predicted payoff (75.00). There are, however, no significant differences between the actual and the predicted average payoff in both bonus team-based compensation schemes. Again, payoffs are quite stable over time.

Analysing the change in effort contribution over rounds in low bonus team yields a falling trend, similarly as in pure team. The Pearson correlation coefficients in low bonus team of 0.3535 reported in Table 2 is significantly more often negative than positive (Binomial test, event probability $\alpha=0.5, p=0.0193$ ). When analysing the change in behaviour over rounds in high bonus team the visual impression of Figure 1 is confirmed: The average Pearson correlation coefficient in high bonus team of -0.0735 is astonishingly close to zero. In fact, we do not observe a significant trend of effort in the treatment high bonus team.

\subsection{Comparison of behaviour between compensation schemes with and without a bonus}

According to the theoretical prediction agents under a bonus team-based compensation scheme should choose a higher effort level than under a purely team-based compensation scheme. Thus, from a theoretical point of view a difference in the amount of effort between pure team and low bonus team as well as between pure team and high bonus team should be observed. A comparison between the average effort level in pure team and low bonus team, however, yields no significant difference at a conventional level. If one compares the effort in 
the compensation scheme without and with a high relative reward it turns out that on average effort is indeed higher if a large bonus is awarded (Mann-Whitney U-test, $p=0.000$, onetailed).

\section{Observation "Effort":}

(i) Average effort is not higher in low bonus team than in pure team.

(ii) Average effort is higher in high bonus team than in pure team.

Thus, additionally rewarding team members according to their relative performance significantly increases their effort only when the relative reward is high. Note, that this is true although on average the total wage sum for a given effort level is constant across treatments. A comparison of the cumulative distributions of effort in pure team, low bonus team and high bonus team in Figure $2 \mathrm{a}$ visualises this result. The cumulative distributions in all three treatments progress almost parallel, with the distribution in high bonus team lying clearly below the distribution in pure team and low bonus team. While in pure team 50 percent of all effort choices are below an effort of 30, in low bonus team this cumulative frequency is reached at an effort of 40 and in high bonus team at an effort of 55. The cumulative distributions in pure team and low bonus team are very much alike.

In all three treatments, pure team, low bonus team and high bonus team, the costs of effort are significantly higher than the costs of effort predicted in equilibrium. Since the equilibrium efforts in low bonus team and high bonus team are higher than the equilibrium effort in pure team, one should expect that the average cost of effort in the bonus team-based compensation schemes is higher than in pure team. In fact, this is true for the high bonus team setting (Mann-Whitney U-test, $p=0.000$, one-tailed) but not for the low bonus team setting.

Former experiments have shown a high variability of efforts over rounds in tournaments (BUll et al. 1987, VAN DiJK et al. 2001, HARBring and IRLENBUSCH 2003). On average subjects choose about the equilibrium effort, but their actual effort levels are very different over time. BuLL et al. (1987) attribute the high variance in effort to the strategic interaction which takes place in tournaments. Some players might strain themselves and strive for winning the tournament while others might resign and drop out by exerting very low effort (MÜLLER and SCHOTTER 2005). Thus, we hypothesise that the introduction of a relative reward will raise the variance in effort. Surprisingly, already in the treatment pure team without a competitive element a high average standard deviation in effort choices is observed (Table 2) which might reflect the presence of different types of players, for example free 
riders and conditional cooperators. Nevertheless, the average standard deviation in effort choices in the treatment high bonus team is even higher (Mann-Whitney U-test, $p=0.050$, one-tailed). Such a significant difference is not observed when comparing the treatment with a low relative reward and the one without.

As shown above, the efficient effort level is equal for all three treatments, since the costs for the additional bonuses are covered in equal parts by all subjects. Thus, there is no difference between the three treatments in terms of the achievable efficiency level. However, in the experiment we do observe different actual efficiency levels, at least for high bonus team. The average payoff and, hence, also efficiency are significantly lower in the treatment pure team than in the treatment high bonus team (Mann-Whitney U-test, $p=0.002$, two-tailed). Of course, this result is driven by higher effort levels which are actually chosen in the combined compensation scheme.

\section{Observation "Efficiency":}

(i) Efficiency is not higher in low bonus team than in pure team.

(ii) Efficiency is higher in high bonus team than in pure team.

Thus, agents under the team-based compensation scheme with a high bonus earn significantly more than agents in the one without a relative reward. Such an effect is not observed for a team-based compensation with a low bonus.

The previous sections already discuss the trend of effort over rounds. Obviously, there is a difference in the alteration of effort choices over time in treatments. While in the treatments pure team and low bonus team effort significantly decreases over rounds, it is quite constant in the treatment high bonus team. Thus, a high tournament incentive in the team-based compensation scheme seems to stabilise the average amount of the exerted effort.

\section{Observation "Trend":}

(i) While a declining trend of average effort is observed in pure team and low bonus team

(ii) effort appears to be quite stable in high bonus team.

This result is surprising. Like in many experiments on public goods provision games in the treatments pure team and low bonus team agents start with highly cooperative effort levels which decrease over rounds. The presence of a high relative reward seems to crowd out voluntary cooperation (i.e., the willingness to exert effort above the individual rational level) and seems to prevent high over-contributions already in the beginning. 
Figure 3: Average over-contributions

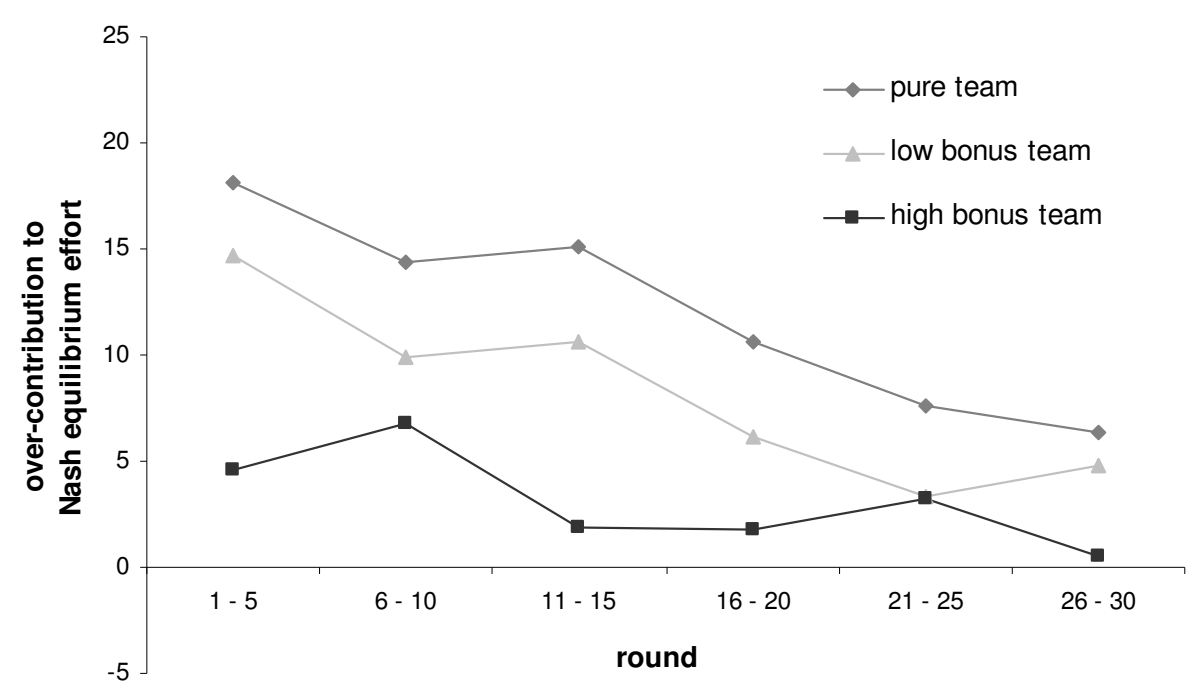

Data points are averages over five rounds.

Figure 3 depicts the development of average over-contributions over time measured as the difference between the observed efforts and the Nash equilibrium predictions in the three treatments. It is evident from the visual inspection of Figure 3 that over-contributions are highest under the pure team compensation scheme. Actual over-contributions are lower in the treatment low bonus team. However, in both treatments they diminish over rounds. In high bonus team the over-contributions are again considerably lower than in the other two treatments and they are quite stable over rounds. Applying the Jonckheere-Terpstra test confirms that the over-contributions significantly diminish with an increasing bonus $(p=0.009$, one-tailed $){ }^{16}$

\section{Observation “Crowding Out of Voluntary Cooperation”:}

Over-contributions relative to the equilibrium decrease with higher bonuses.

Note that due to the convex cost function over-contributing an additional effort unit is more costly if the effort level is already high. This, however, cannot be the only reason for the difference in over-contributions since in the first half of the experiment (round 1-15) also the costs for effort exerted above the equilibrium level are higher in pure team than in high bonus team (average costs of over-contributions in round 1-15 in pure team: 20.42; high bonus

\footnotetext{
${ }^{16}$ However, not all pair-wise comparisons between over-contributions are significant (Mann-Whitney U-test, pure team - low bonus team: $p=0.205$, low bonus team - high bonus team: $p=0.099$, pure team - high bonus team: $p=0.006$, all one-tailed).
} 
team: 15.87; Mann-Whitney U-test, $p=0.050$, one-tailed). ${ }^{17}$ Thus, we indeed find that the exertion of effort above the individually rational level is crowed out especially if a high bonus is introduced. Increasing extrinsic motivation by paying out an individual bonus therefore is not only beneficial but comes with a cost. To understand the dynamics of the resulting tradeoff caused by introducing a bonus more deeply we investigate the adjustment of agents' behaviour over time in the different treatments.

\subsection{Individual adjustment of effort choices over rounds}

At the end of each period subjects are able to observe the total output of the group. Thus, they can estimate the average contribution in the group. Remember that the expected value of the random variable is 0 . The question arises whether subjects raise their effort if they think that their effort exerted has been lower than the average effort. Analogously, do subjects who think that their effort exerted has been higher than the average effort lower their effort? Similar adjustment processes are observed by SELTEN and STOECKER (1986), SELTEN and Buchta (1998), and Selten and OcKenfels (2005). The data reveals that in all our treatments subjects indeed lower their effort in the next period more often than they raise it when they observe that their effort in the current period was higher than the average output of a team member (Wilcoxon-Signed Rank test, pure team: $p=0.002$; low bonus team: $p=$ 0.000; high bonus team: $p=0.000$, one-tailed). Also the reverse effect is significant: Subjects whose effort level in the current period is below the average output of a team member raise their effort in the following period more often than they lower it (Wilcoxon-Signed Rank test, pure team: $p=0.000$; low bonus team: $p=0.000$; high bonus team: $p=0.000$, one-tailed).

We find, however, some interesting differences between treatments. Only in the treatment with a low bonus subjects lower their effort in the following period to a greater extent than in the pure team after having observed that the other team members on average had exerted

17 From the average effort levels depicted in Figure 1 one could gain the impression that one reason for the higher over-contributions in pure team is that subjects choose an effort level somewhere in the middle (for example, 50) as a focal effort level and from there converge to the equilibrium over time. However, if one analyses the individual behaviour more closely it becomes clear that over-contributions in pure team are very likely to be high for other reasons, as individual first round effort levels vary immensely in all three treatments (standard deviations: 36.09 in pure team; 33.53 in low bonus team and 32.02 in high bonus team). To further control for the conjecture (of choosing something around 50 and then converging to the equilibrium) we ran an additional control treatment with 6 independent observations. The control treatment is identical to our pure team treatment with the only difference that the equilibrium solution is exactly 50 (this was implemented by lowering the effort costs by choosing $\left.C\left(e_{i}\right)=e_{i}^{2} / 200\right)$. Although we kept the range of feasible effort levels $(0, \ldots, 120)$ the same as in the other treatments, we also observe high over-contributions (starting with an average first round effort of around 76) which diminish over time. In fact, the contributions in the control sessions are 
lower average effort (Mann-Whitney U-test, low bonus team - pure team: $p=0.050$; high bonus team - pure team: $p=0.362$,one-tailed). This observation supports our conjecture that the co-operative attitude of team members is higher in pure team than if an additional bonus is provided. Although a bonus individually creates incentives to exert higher effort, it somehow seems to destroy the extent of willingness to contribute to the team if other team members had underperformed in the past. This is the case at least if the bonus is low. In the high bonus team treatment we do not observe such an effect but here team members are likely to be reluctant to reduce their effort too much because of the high bonus.

In the treatments low bonus team and high bonus team subjects either receive a winner or a loser prize. Thus, there is a second source of information from which subjects can estimate the behaviour of the other group members. Winning the tournament means that one's own output in the group was highest, losing the tournament means that there was at least one group member whose output was higher. We indeed observe that subjects do react to the received prize. In both team-based compensation schemes with a relative reward for the highest contributor in the team, subjects who received the winner prize lower their effort in the next period significantly more often than they raise it (Wilcoxon-Signed Rank test, low bonus team: $p=0.000$; high bonus team: $p=0.012$, one-tailed). Analogously, subjects who received the loser prize raise their effort in the next period significantly more often than they lower it (Wilcoxon-Signed Rank test, low bonus team: $p=0.000$; high bonus team: $p=0.000$, onetailed). We observe that in high bonus team subjects who have won the bonus and lower their effort afterwards do this on average by 41.37 which is significantly higher than the change of 11.92 if they raise it (Wilcoxon-Signed Rank test, $p=0.000$, one-tailed) ${ }^{18}$. In the same situation subjects in low bonus team lower their effort by 25.21 which is again significantly higher than the change of 11.79 if they raise it (Wilcoxon-Signed Rank test, $p=0.000$, onetailed). After not being awarded the bonus no significant difference in the magnitude between the directions of effort changes is observed in both bonus team-based compensation schemes. Subjects who do not receive the bonus and raise their effort in the next period on average

significantly higher than the effort chosen in the high bonus treatment (in which the equilibrium prediction is also 50).

18 A lowering adjustment of 41.37 in high bonus team might appear quite high. In fact, average efforts of reward winners and losers turn out to be more apart from each other in this treatment than in low bonus team. Average effort of reward winners in high bonus team is 77.64 (low bonus team 55.14). Average effort of reward losers in high bonus team is 44.95 (low bonus team 32.64). Variance of effort is higher in high bonus team than in low bonus team. Moreover, reward winners exert an inefficient effort above 100 in $19 \%$ of the winning cases (low bonus team 5\%). Actually, to some extent team members seem to alternate in receiving the reward (- on 
raise it by 26.89 in high bonus team and by 19.54 in low bonus team; Subjects who do not receive the bonus and lower their effort in the next period on average lower it by 26.53 in high bonus team and by 21.00 in low bonus team. (see Table 3).

Table 3: Effort adjustment dependent on the received bonus

\begin{tabular}{|c|c|c|c|c|}
\hline \multirow{5}{*}{$\begin{array}{l}\text { after obtaining a } \\
\text { winner prize } \\
\text { in the last period } \\
\text { - } \\
348 \text { instances }\end{array}$} & \multirow[b]{3}{*}{ high bonus team } & \multicolumn{3}{|c|}{ average effort adjustment } \\
\hline & & \multicolumn{2}{|c|}{ if increased } & \multirow{2}{*}{$\begin{array}{c}\text { if decreased } \\
41.37 \\
(132)\end{array}$} \\
\hline & & $\begin{array}{c}11.92 \\
(93)\end{array}$ & $\begin{array}{l}<* * * \\
(<* *)\end{array}$ & \\
\hline & low bonus team & $\begin{array}{c}11.79 \\
(86)\end{array}$ & $\begin{array}{l}<* * * \\
(<* * *)\end{array}$ & $\begin{array}{l}25.21 \\
(174)\end{array}$ \\
\hline & pure team (hypothetical) & $\begin{array}{c}21.99 \\
(84)\end{array}$ & $\begin{array}{l}<* * * \\
(<* * *)\end{array}$ & $\begin{array}{l}40.45 \\
(157)\end{array}$ \\
\hline after obtaining a & high bonus team & $\begin{array}{l}26.89 \\
(478)\end{array}$ & $\begin{array}{c}\approx \\
(>* * *)\end{array}$ & $\begin{array}{l}26.53 \\
(319)\end{array}$ \\
\hline $\begin{array}{l}\text { loser prize } \\
\text { in the last period } \\
\text { - }\end{array}$ & low bonus team & $\begin{array}{l}19.54 \\
(443)\end{array}$ & $\begin{array}{c}\underset{(>* * *)}{\approx} \\
(>\end{array}$ & $\begin{array}{l}21.00 \\
(310)\end{array}$ \\
\hline 1044 instances & pure team (hypothetical) & $\begin{array}{l}21.03 \\
(413)\end{array}$ & $\begin{array}{c}\approx \\
(>* * *)\end{array}$ & $\begin{array}{l}23.08 \\
(257)\end{array}$ \\
\hline
\end{tabular}

Figures in parentheses indicate the number of cases in which effort has been adjusted to the respective direction.

Since subjects cannot react to the received prize in the final period, we consider 29 (rounds) $x 12$ (groups) $x 1$ (winner prize) $=348$ obtained winner prizes. An analogous basis underlies the comparison regarding the loser prizes: 29 (rounds) x 12 (groups) $x 3$ (loser prizes) $=1044$ obtained loser prizes.

The Wilcoxon-Signed Rank test for dependent pairs (one-tailed) was applied. The level of significance at which the null hypothesis can be rejected in favour of the directional alternative hypotheses is depicted as follows:

$\begin{array}{lll}* * * & \text { highly significant: } & p \leq 0.01 \\ * * & \text { significant: } & 0.01<p \leq 0.05\end{array}$

For the reason of comparison we evaluate the behaviour in the treatment pure team according to hypothetically obtained bonuses which we imaginarily assign to the agent with the highest output. We observe that subjects with the highest output in the group do lower their effort in the following period more often than they raise it (Wilcoxon-Signed Rank test, $p=0.000$, one-tailed). Analogously, subjects whose output is not the highest in the group raise their effort more often than they lower it (Wilcoxon-Signed Rank test, $p=0.000$, one-tailed). The average effort adjustments and their comparisons can be found in more detail in Table 3. If agents received the loser prize the adjustments in both directions are roughly of the same magnitude in all three treatments. However, in all treatments the lowering adjustments are of greater extent than the raising adjustments after agents have received the winner prize. 


\section{A Pure Bonus Compensation Scheme}

Why do we observe smaller over-contributions in high bonus team than in pure team? One reason could be that pure tournament incentives induce under-contribution which would cancel out in high bonus team with the over-contributions typically induced by the pure team compensation. Why do we observe no declining trend of effort in high bonus team although it is present in pure team? Maybe pure tournament incentives induce an increasing pattern of effort contributions which again might cancel out with the declining trend of effort observed in the pure team setting. To investigate these questions and to gain a deeper understanding of the effectiveness of a relative reward within a team-based compensation scheme we conducted another treatment pure bonus in which a tournament incentive scheme is implemented exclusively. Analogously to the treatment high bonus team subjects compete for one bonus $\Delta$ defined as the difference between the winner prize $M$ and a loser prize $m$ but there is no team compensation component. ${ }^{19}$

As above we consider a set of agents $i(i=1, \ldots, n)$ who simultaneously choose their effort levels $e_{i}$. The output $y_{i}=e_{i}+\varepsilon_{i}$ of agent $i$ is determined by the production function presented in (1) with a random variable $\varepsilon_{i}$ which is uniformly distributed over the interval $[-\bar{\varepsilon},+\bar{\varepsilon}]$. Costs of effort $C\left(e_{i}\right)$ are described by the same convex function as used in the treatments above (a convex cost function of the type $C\left(e_{i}\right)=e_{i}^{2} / \bar{c}$ with a fixed constant $\bar{c}$ ). The expected payoff for agent $i$ is given by

$$
\Pi_{i}^{\text {pure_bonus }}=m+\varphi_{i}\left(e_{1}, \ldots, e_{n}\right) \Delta-C\left(e_{i}\right)
$$

with $\varphi_{i}\left(e_{1}, \ldots, e_{n}\right)$ denoting the probability for agent $i$ to win the bonus $\Delta$. The following firstorder condition has to be fulfilled:

$$
\frac{\partial \varphi_{i}\left(e_{1}, \ldots, e_{n}\right)}{\partial e_{i}} \Delta=\frac{2 e_{i}}{\bar{c}}
$$

Together with the marginal probability of winning (see equation (7)) we obtain the equilibrium effort in the tournament setting ${ }^{20}$ :

\footnotetext{
${ }_{19}$ As we observe a significant difference between pure team and high bonus team we concentrate our additional analysis of a pure bonus compensation scheme solely on the case of a high relative reward.

${ }^{20}$ The agents should have an incentive to exert strictly positive effort levels, i.e., the participation constraint $\Delta / n \geq c\left(e^{*}\right)$ has to be fulfilled for each player. This is the case given the parameters chosen in the experiment.
} 


$$
e_{\text {pure_bonus }}^{*}=\frac{\bar{c} \Delta}{4 \bar{\varepsilon}}
$$

In a pure tournament incentive scheme the wage sum does not depend on the amount of effort exerted. Thus, from the sole perspective of the team (because there is no team compensation component) it is efficient to exert no effort at all in order to save the costs while the bonus is given to one of the agents anyway.

$$
e_{\text {pure_bonus }}^{\text {eff }}=0
$$

In the experiment we investigate a tournament setting as comparable as possible to the settings described above. ${ }^{21}$ Table 4 shows our experimental design and the equilibrium effort for the additional pure bonus treatment. Again, we consider groups of four agents.

Table 4: Experimental design of pure bonus

\begin{tabular}{cccccccccc}
\hline \hline & \multicolumn{2}{c}{ Design } & & \multicolumn{2}{c}{ Parameters } & \multicolumn{2}{c}{ Predictions } \\
& \# rounds & \# participants $\begin{array}{c}\text { \# independent } \\
\text { observations }\end{array}$ & $m$ & $\Delta$ & cost & $\begin{array}{c}\text { Nash } \\
\text { equilibrium } \\
\text { effort }\end{array}$ & $\begin{array}{c}\text { efficient } \\
\text { effort }\end{array}$ \\
\cline { 2 - 9 } pure bonus & 30 & 48 & 12 & 50 & 60 & $e^{2} / 100$ & 25 & 0 \\
\hline \hline
\end{tabular}

Table 5 provides an overview of the main results in pure bonus. First of all, one can see that the average effort in pure bonus is quite close to the effort predicted by theory. On average subjects in pure bonus earn less than in equilibrium and we observe a decreasing trend of effort in pure bonus. The Binomial test shows that the Pearson correlation coefficients computed for each independent observation is significantly more often negative than positive (event probability $\alpha=0.5, p=0.0193$ ). Subjects start off with a higher average effort in comparison to the equilibrium effort and on average they reduce effort over rounds to even below the equilibrium effort. Thus, in both pure compensation schemes we observe a decreasing trend of effort over rounds. Therefore the stable effort level in the composed high bonus compensation scheme cannot be explained by opposite trends in the two underlying pure schemes.

\footnotetext{
${ }^{21}$ In order to reduce potential effects from loss aversion on effort choices (FALK and FeHR, in progress) we decided to implement a strictly positive loser prize $m=50$. Note that a positive loser price does not change the equilibrium effort as the effort only depends on the size of $\Delta$.
} 
Table 5: Overview of average results in pure bonus

\begin{tabular}{|c|c|c|c|c|c|}
\hline \multirow{3}{*}{ pure bonus } & average effort & $\begin{array}{l}\text { standard deviation of } \\
\text { effort over rounds }\end{array}$ & average payoff & average cost & $\begin{array}{l}\text { trend over } \\
\text { rounds }\end{array}$ \\
\hline & $\begin{array}{c}27.77 \\
(25.00)\end{array}$ & 27.89 & $\begin{array}{l}49.51^{--} \\
(58.75)\end{array}$ & $\begin{array}{c}15.49^{+++} \\
(6.25)\end{array}$ & $-0.237^{* *}$ \\
\hline & \multicolumn{5}{|c|}{ treatment differences } \\
\hline $\begin{array}{l}\text { pure bonus - } \\
\text { pure team }\end{array}$ & $p=0.007$ & $p=0.489$ & $p=0.378$ & $p=0.030$ & $p=0.205$ \\
\hline $\begin{array}{l}\text { pure bonus - } \\
\text { high bonus team }\end{array}$ & $p=0.000$ & $p=0.017$ & $p=0.000$ & $p=0.000$ & $p=0.099$ \\
\hline
\end{tabular}

Equilibrium values are given in parentheses. The trend over rounds is indicated by the average Pearson correlation coefficient. Significance levels of treatment differences result from Mann-Whitney U-tests (one-tailed).

By using the Binomial test (one-tailed) we state the level of significance at which the null hypothesis can be rejected in favour of the alternative hypothesis that the average values are more often above (below) the equilibrium level than below (above):

$+++\cdots$ highly significantly above / below the equilibrium level: $\quad p \leq 0.01$

$+\quad$ significantly above the equilibrium level: $\quad 0.01 \leq p \leq 0.05$

By using the Binomial test (one-tailed) we state the level of significance at which the null hypothesis can be rejected in favour of the alternative hypothesis that the Pearson correlation coefficient is more often negative than positive:

** $\quad$ significantly more often negative than positive: $\quad 0.01 \leq p \leq 0.05$

Going back to equation (8) we already discussed that the equilibrium effort played in the bonus team treatments is determined by two additive components: the equilibrium effort played in pure team augmented by the analogous pure bonus equilibrium effort. Thus, from a theoretical perspective we should expect that the sum of the average efforts in the treatments pure team and pure bonus should add up to the average effort in the treatment high bonus team. If the tournament incentive would induces effort below the individual rational level this could be a reason for the low over-contributions in high bonus team. However, we do not observe such an under-contribution in pure bonus: The average effort in pure team amounts to 37.04 while the average effort in pure bonus is 27.77 . Thus, the sum of the average efforts of both pure treatments (64.81) is clearly higher than the average effort observed in high bonus team (53.12). ${ }^{22}$ This confirms our impression that the combined bonus team incentive scheme suffers from crowding out of voluntary cooperation.

\footnotetext{
22 If one adds the overall average effort observed in the treatment pure bonus to the average efforts of each independent observation in the treatment pure team and tests these values against the average efforts observed in the treatment high bonus team one obtains that the former are significant higher than the latter (Mann-Whitney U-test, $p=0.004$, two-tailed). This is also true if one adds the overall average effort observed in the treatment pure team to the average efforts of each independent observation in the treatment pure bonus and tests these values against the average efforts observed in the treatment high bonus team (Mann-Whitney U-test, $p=0.002$, two-tailed).
} 


\section{Conclusion}

This paper experimentally investigates the incentive effects of a compensation package often observed in business organisations: team-based compensation with an additional relative reward for the highest contributor in the team. From a theoretical point of view an additional bonus within a team-based compensation scheme should increase output since the individual incentives can be separated into two additive components: the team incentive component and the tournament incentive component. If the bonus is high in the experiment we indeed observe a significant increase in effort which is not the case if the bonus is low. In the pure team compensation scheme and when the bonus is low we observe high over-contributions (i.e., voluntary cooperation above the individually rational level) which decline over rounds. Surprisingly, this standard result known from public goods experiments disappears if the bonus is high. In the team-based compensation scheme with the high bonus average effort is quite stable, although right from the beginning on a very low over-contribution level. It seems that an additional, substantial bonus awarded to only one of the team members induces higher effort but crowds out voluntary cooperation.

Given these observations designers of compensation packages face a trade-off when introducing a tournament structure into a team setting. Relative rewards are likely to have counteracting effects. On the one hand, they increase output because of higher individual incentives. On the other hand, there are drawbacks from distracting team members to act cooperatively. The net result from these two effects is not obvious. We have seen that when the bonus is small crowding-out of voluntary cooperation is not a big issue but individual incentives remain on a relatively low level. With a high relative reward individual incentives clearly increase but might come with the cost of a diminished cooperative attitude. In this sense, our results advise some caution for the implementation of tournament incentives into team-based compensation.

Why exactly does a high relative bonus reduce voluntary cooperation? Evidence from previous public goods experiments suggests that participants over-contribute (above the individually rational level) for strategic reasons. By contributing highly in the beginning they seem to aim at creating a cooperative atmosphere in the group to convince others to contribute highly as well. Naturally such an investment in creating cooperation pays off more in earlier rounds than in later ones. Competition introduced by a bonus for one of the team members seems to destroy the cooperative attitude within the team. One reason might be that relative 
rewards do not only create winners but leave also losers who could considerably be discouraged from contributing to the team's task (MÜLLER and SCHOTTER 2005). Another reason might be that participants perceive a pure team situation with equal payoff-sharing differently than a team situation in which members compete for a bonus. Such a framing effect induced by different compensation schemes (IRLENBUSCH and SLIWKA 2006) might enable team members to focus more on the potential gains from voluntary cooperation under the pure team incentive scheme than under a pronounced tournament structure. Under the latter they might primarily see their team mates as competitors which reduces the scope for cooperation. To analyse these and other explanations for the detailed mechanisms behind the observed crowding-out effect in teams appears to be a promising field for further research.

Additional studies are also needed to investigate whether the observed crowding-out effect can be mitigated and whether the decline of cooperation can be damped. It could well be that alternative procedures for awarding the bonus can preserve the cooperative attitude in the team, for example, by increasing team members' participation through majority voting. Additionally, in our study we abstract from peer effects which certainly play a significant role in teams (FALK and ICHINO 2006). It would be quite interesting to analyse whether peer pressure could help to sustain cooperation in a team when a relative reward is introduced. Another interesting question emerges from the observed decreasing trend in voluntary cooperation. Is there a way to stop or reduce this decline? The study by ISAAC, WALKER and WILLIAMS (1994) provides some hints that the decline becomes flatter the longer the time period during which the team members interact. This would suggest that the life-span of a team should not be too short. The observed crowding-out of voluntary cooperation by a relative reward appears to be even more problematic when team members have the possibility to sabotage each other. Sabotage is indeed known to be exerted in tournaments in order to improve the own position in a ranking for rewards (HARBRING and IRLENBUSCH 2005). We consider our study as a starting point for investigating crowding out of voluntary cooperation in teams through compensation schemes which introduce individual competition. By bringing up the above questions we hope that our observations do not only suggest practical implications for providing incentives in teams but also point at several interesting issues for further research. 


\section{References}

Alchian, Armen and Demsetz, Harold (1972): Production, Information Costs, and Economic Organization, American Economic Review 62, 777-795.

ANDREOnI, James (1988): Why Free Ride? Strategies and Learning in Public Goods Experiments, Journal of Public Economics 37, 291-304.

ANDREONI, James (1995): Cooperation in Public-Goods Experiments: Kindness or Confusion?, American Economic Review 85(4), 891-904.

Beyerlein, Michael M. (ed.) (2000): Work Teams: Past, Present and Future, Kluwer Academic, Boston.

Bohnet, Iris; Frey, Bruno, S. and Huck, Steffen (2001): More Order with Less Law: On Contract Enforcement, Trust, and Crowding, American Political Science Review 95(1), 131-144.

Bowles, Samuel (2005): Social Preferences and Public Policy: Are Good Laws a Substitute for Good Citizens?, Working Paper, Santa Fe Institute.

Bull, Clive; Schotter, Andrew and Weigelt, Keith (1987): Tournaments and Piece Rates: An Experimental Study, Journal of Political Economy 95, 1-33.

CAmerer, Colin F. (2003): Behavioral Game Theory - Experiments in Strategic Interaction, Princeton University Press, Princeton.

CAmeron, Judy and PiErce, W. David (1994) Reinforcement, Reward, and Intrinsic Motivation: A Meta Analysis, Review of Educational Research 64, 363-423.

CROSON, Rachel (1996): Partners and Strangers Revisited, Economics Letters 53, 25-32.

Croson, Rachel (2001): Feedback in Voluntary Contribution Mechanisms: An Experiment in Team Production, Research in Experimental Economics 8, 85-97.

DAVIS, Douglas D. and Holt, Charles A. (1993): Experimental Economics, Princeton University Press, Princeton.

DECI, Edward L. (1971): Effects of Externally Mediated Rewards on Intrinsic Motivation, Journal of Personality and Social Psychology 18, 105-115.

DecI, Edward L.; KoEstner, Richard and Ryan, Richard M. (1999): The Undermining Effect Is a Reality after All, Psychological Bulletin 125, 692-700.

DeMatteo, Jacquelyn S.; Eby, Lillian T. and Sundstrom, Eric (1998): Team-Based Rewards: Current Empirical Evidence and Directions for the Future Research, Research in Organizational Behavior 20, 141-183.

Dickinson, David L. (2001): The Carrot vs. the Stick in Work Team Motivation, Experimental Economics 4, 107-124.

DiCKInSON, David L. and ISAAC, Mark R. (1998): Absolute and Relative Rewards for Individuals in Team Production, Managerial and Decision Economics 19, 299-310.

VAN DiJK, Frans; Sonnemans, Joep and VAn WINDEN, Frans (2001): Incentive Systems in a Real Effort Experiment, European Economic Review 45, 187-214.

EISENBERGER, Robert and CAMERON, Judy (1996): Detrimental Effects of Reward: Reality of Myth? American Psychologist 51, 1153-1166.

FALK, Armin and FEHR, Ernst (work in progress): The Power and Limits of Tournament Incentives, personal communication.

FALK, Armin and Kosfeld, Michael (2006): Distrust - The Hidden Cost of Control, forthcoming in: American Economic Review.

FALK, Armin and ICHINO, Andrea (2003): Clean Evidence on Peer Effects, Journal of Labor Economics 24(1), 39-57.

FALK, Armin and FEHR, Ernst (2003): Why labour market experiments? Labour Economics 10, 399-406. 
FEHR, Ernst and GäCHTER, Simon (2000): Do Incentive Contracts Crowd Out Voluntary Cooperation?, Working Paper No. 34, University of Zürich.

FEHR, Ernst and FALK, Armin (2002): Psychological Foundations of Incentives, European Economic Review 46, 687-724.

FeHR, Ernst and RocKenBACH, Bettina (2003): Detrimental Effects of Sanctions on Human Altruism, Nature $422,137-140$.

FEHR, Ernst and LIST, John A. (2004): The Hidden Costs and Returns of Incentives - Trust and Trustworthiness among CEOs, Journal of the European Economic Association 2(5), 743-771.

FeHR, Ernst; KLEIN, Alexander and SchmidT, Klaus (2006): Fairness and Contract Design, forthcoming in: Econometrica.

FISCHBACHER, Urs (1999): z-Tree: Zurich Toolbox for Readymade Economic Experiments, Working Paper No. 21, Institute for Empirical Research in Economics, University of Zürich.

Frey, Bruno S. (1997): Not Just For The Money - An Economic Theory of Personal Motivation, Edward Elgar Publishing, Cheltenham.

Frey, Bruno S. and Oberholzer-GeE, Felix (1997): The Cost of Price Incentives: An Empirical Analysis of Motivation Crowding-Out, American Economic Review 87, 746-755.

FreY, Bruno S. and JEgEn, Reto (2001): Motivation Crowding Theory, Journal of Economic Surveys 15(5), 589-611.

GÄCHTER, Simon; KeSSLER, Esther and KöNIGSTEIN, Manfred (2005): Performance Incentives and the Dynamics of Voluntary Cooperation, Working Paper, University of Nottingham and University of Erfurt.

GNEEZY, Uri (2005): The W Effect of Incentives, Working paper, University of Chicago.

GNEEZY, Uri and Rustichini, Aldo (2000a): Pay Enough or Don't Pay at All, Quarterly Journal of Economics 115(3), 791-810.

GneEZY, Uri and Rustichini, Aldo (2000b): A Fine is a Price, Journal of Legal Studies 29, 1-17.

HAMILTON, Barton H.; NickERSON, Jack A. and OwAN, Hideo (2003): Team Incentives and Worker Heterogeneity: An Empirical Analysis of the Impact of Teams on Productivity and Participation, Journal of Political Economy 111, 465-497.

HANSEN, Daniel (1997): Worker Performance and Group Incentives: A Case Study, Industrial and Labor Relations Review 51, 37-49.

Harbring, Christine and Irlenbusch, Bernd (2003): An Experimental Study on Tournament Design, Labour Economics 10, 443-464.

HARBring, Christine and IRLENBUSCH, Bernd (2005): Incentives in Tournaments with Endogenous Prize Selection, Journal of Institutional and Theoretical Economics 161, 636-663.

HeAtH, Chip (1999): On the Social Psychology of Agency Relationships: Lay Theories of Motivation Overemphasize Extrinsic Incentives, Organizational Behavior and Human Decision Processes 78, 25-62.

Heneman, Robert L. and vON HIPPEL, Courtney (1995): Balancing Group and Individual Rewards: Rewarding Individual Contributions to the Team, Compensation and Benefits Review 27, 63-68.

HolmströM, Bengt (1982): Moral Hazards in Teams, Bell Journal of Economics 13, 324-340.

VAn Hootegem, Geert; Benders, Jos; Delarue, Anne and Procter, Stephen (2005): Teamworking: Looking Back and Looking Forward, International Journal of Human Resource Management 16, 167-173.

Houser, Daniel and Kurzban, Robert (2002): Revisiting Kindness and Confusion in Public Goods Experiments, American Economic Review 92(4), 1062-1069.

IsAAC, R. Mark; WALKer, James M. and ThOMAS, Susan H. (1984): Divergent Evidence on Free Riding: An Experimental Examination of Possible Explanations, Public Choice 43, 113-149.

ISAAC, R. Mark; WALKeR, James M. and Williams, Arlington (1994): Group Size and the Voluntary Provision of Public Goods: Experimental Evidence Utilizing Large Groups, Journal of Public Economics 54, 1-36. 
IRLENBUSCH, Bernd and SliwKA, Dirk (2006): Incentives, Decision Frames and Motivation Crowding Out - An Experimental Investigation, mimeo, University of Cologne and London School of Economics.

KeSER, Claudia (1996): Voluntary Contribution to Public Good when Partial Contribution Is a Dominant Strategy, Economic Letters 50, 359-366.

KESER, Claudia (2000): Strategically Planned Behavior in Public Good Experiments, CIRANO working paper $2000 s-35$.

LAZEAR, Edward P. and RosEn, Sherwin (1981): Rank-Order Tournaments as Optimum Labor Contracts, Journal of Political Economy 89, 841-864.

LEDYARD John, O. (1995): Public Goods: A Survey of Experimental Research, in: KagEL, John H. and RoTH, Alvin E. (ed.): Handbook of Experimental Economics, Princeton University Press, Princeton, 111-194.

LEPPER, Mark, R.; GreEnE, David and NISBETT, Richard E. (1973) Undermining Children's Intrinsic Interest with Extrinsic Rewards: A Test of the "Overjustification" Hypothesis, Journal of Personality and Social Psychology 28, 129-37.

MaIN, Brian G. M., O’ReIlly, Charles A. III, and WADE, James (1993): Top Executive Pay: Tournament or Teamwork? Journal of Labor Economics 11, 606-28.

MANTHEI, Kathrin (2006): Pay - But Don't Pay too Much, forthcoming in: Journal of Economic Behavior and Organization

Mueller, Frank; Procter, Stephan and Buchanan, David (2000): Teamworking in its Context: Antecedents, Nature and Dimensions, Human Relations 53, 1387-1424.

MülleR, Wieland and SchotTer, Andrew (2005): Workaholics and Drop Outs in Optimal Organizations, Discussion paper, New York University.

Muller, Laurent; SEFTON, Martin; SteInBERG, Richard and VeSTERLUND, Lise (2006): Strategic Behaviour and Learning in Repeated Voluntary-Contribution Experiments, Discussion Paper, University of Nottingham.

MurPHY, Kevin (1992): Performance Measurement and Appraisal: Motivating Managers to Identify and Reward Performance, in BRUns, William J. Jr. (ed.): Performance Measurement, Evaluation, and Incentives, Harvard Business School Press, Boston, 37-62.

NAlbantian, Haig R. and SchotTer, Andrew (1997): Productivity under Group Incentives: An Experimental Study, American Economic Review 87, 314-341.

Newhouse, Joseph (1973): The Economics of Group Practice, Journal of Human Resources 8, $37-56$.

OrRison, Alannah; SchotTer, Andrew and Weigelt, Keith (2004): Multiperson Tournaments: An Experimental Examination, Management Science 50, 268-279.

Palfrey, Thomas R. and Prisbrey, Jeffrey E. (1996): Altruism, Reputation, and Noise in Linear Public Goods Experiments, Journal of Public Economics 61, 409-27.

PfeFFER, Jeffrey and SutTon, Robert. I. (1999): The Knowing-Doing Gap: How Smart Companies Turn Knowledge into Action, Harvard Business School Press, Cambridge.

Pittmann, Thane S. and Heller, Jack F. (1987): Social Motivation, Annual Review of Psychology 38, 461-89.

PRAT, Andrea (2002): Should a Team be Homogenous?, European Economic Review 46, 1187-1207.

Rajan, Madhav V. and ReICHELstein, Stefan (2006): Subjective Performance Indicators and Discretionary Bonus Pools, Journal of Accounting Research 44(3), 585-618.

Rosenbaum, Milton E.; Moore, Danny I.; Cotton, John L.; CooK, Michael S.; Hieser, Rex A.; Shovar, M. Nicki and GRAY, Morris J. (1980): Group Productivity and Process: Pure and Mixed Reward Structures and Task Interdependence, Journal of Personality and Social Psychology 39, 626-642.

SEFTON, Martin and SteInBERG, Richard (1996): Reward Structures in Public Good Experiments, Journal of Public Economics 61, 263-287.

SElten, Reinhard and StOecker, Rolf (1986): End Behavior in Sequences of Finite Prisoner's Dilemma Supergames, Journal of Economic Behavior and Organization 7, 47-70. 
Selten, Reinhard and BuchtA, Joachim (1998): Experimental Sealed Bid First Price Auctions With Directly Observed Bid Functions, in: Budescu, David; EREv, Ido and ZwICK, Rami (ed.): Games and Human Behavior: Essays in Honor of Amnon Rapoport, Lawrence Erlbaum Associates Inc., Mahawa.

SELTEN, Reinhard and OCKENFEls, Axel (2005): Impulse Balance Equilibrium and Feedback in First Price Auctions, Games and Economic Behavior 51, 155-170.

SUTTER, Matthias (2006): Endogenous versus Exogenous Allocation of Prizes in Teams - Theory and Experimental Evidence, forthcoming in: Labour Economics.

TANG, Shu Hua and Hall, Vernon C. (1995): The Overjustification Effect: A Meta-Analysis, Applied Cognitive Psychology 9, 365-404.

WAGEMAN, Ruth (1995): Interdependence and Group Effectiveness, Administrative Science Quarterly 40, 145 180.

WiERSMA, Uco J. (1992): The Effects of Extrinsic Rewards in Intrinsic Motivation: A Meta-Analysis, Journal of Occupational and Organizational Psychology 65, 101-114.

ZWICK, Thomas (2004): Employee Participation and Productivity, Labour Economics 11, 715-740. 


\section{Appendix: Instructions (Treatment high bonus team)}

(Original instructions were in German. They are available from the authors upon request.)

At the beginning of the experiment three other participants are randomly assigned to you. During the experiment you only interact with the participants to whom you are assigned. This assignment is kept constant during the whole experiment. The identity of the three other participants is not revealed to you.

The costs and payoffs are given in the fictitious currency "taler". Each participant receives a starting capital of 300 taler.

The experiment consists of $\mathbf{3 0}$ rounds.

\section{Procedure of a round:}

1. You choose an integer from $\mathbf{0}$ to $\mathbf{1 2 0}$ and enter the number into the designated field. The number you choose causes a certain cost.

2. For each participant a random number is drawn. Each number has the same probability and is independently drawn from the set $\{-60, \ldots,+60\}$. (Your random number and the random numbers of the other participants are not revealed to you.) The computer calculates the payoffs on the basis of your chosen numbers and the random numbers. This happens as follows:

First of all the result is calculated. The result of each participant is the sum of his chosen number and his individual random number.

\section{Result $=$ chosen number + individual random number}

Thereafter the total result is calculated. The total result is the sum of the results of the four group members.

Total Result $=$ sum of the results of all group members

Your round payoff is equal to 0.5 times the total result plus a possible additional payment minus the cost of the (own) chosen number.

\section{Round Payoff $=0.5 \times$ total result + possible additional payment} - cost of the chosen number

Please note that each group member benefits from all chosen numbers of the four group members: the higher the individual chosen numbers are the higher the total result tends to be.

The participant with the highest result receives an additional payment. The other three participants with the lower results receive no additional payment. The additional payment is 60 taler. If the highest result of two or more participants are equal, a fair random move decides who receives the additional payment.

The costs which are subtracted from each participant for her chosen number can be found in the cost table. In the cost table you find all costs for the numbers from 0 to 120. All participants receive the same cost table.

3. At the end of each round you learn whether you received the additional payment. Moreover your chosen number, your costs for the chosen number, the total result of the group and your round payoff are displayed to you.

4. The next round starts.

Your total payoff from the experiment is the sum of your endowment capital plus all individual 30 round payoffs. At the end of the experiment this amount (in talers) is exchanged at an exchange rate of $1 €$ per 180 taler. 
Please note:

During the whole experiment no communication is permitted. If you have any question, please raise your hand out of the cubicle. All decisions are made anonymously. Also the payout is anonymous, which means that no participant will learn the payout of another participant.

Good luck!

Appendix: Cost table for the treatment pure team

(The costs in the treatment high bonus team (low bonus team) were by 15 (3) higher for each number.)

cost table

\begin{tabular}{|c|c|c|c|c|c|}
\hline number & cost of number & number & cost of number & number & cost of number \\
\hline $\mathbf{0}$ & 0.00 & & & & \\
\hline 1 & 0.01 & 41 & 16.81 & 81 & 65.61 \\
\hline 2 & 0.04 & 42 & 17.64 & 82 & 67.24 \\
\hline 3 & 0.09 & 43 & 18.49 & 83 & 68.89 \\
\hline 4 & 0.16 & 44 & 19.36 & 84 & 70.56 \\
\hline 5 & 0.25 & 45 & 20.25 & 85 & 72.25 \\
\hline 6 & 0.36 & 46 & 21.16 & 86 & 73.96 \\
\hline 7 & 0.49 & 47 & 22.09 & 87 & 75.69 \\
\hline 8 & 0.64 & 48 & 23.04 & 88 & 77.44 \\
\hline 9 & 0.81 & 49 & 24.01 & 89 & 79.21 \\
\hline 10 & 1.00 & 50 & 25.00 & 90 & 81.00 \\
\hline 11 & 1.21 & 51 & 26.01 & 91 & 82.81 \\
\hline 12 & 1.44 & 52 & 27.04 & 92 & 84.64 \\
\hline 13 & 1.69 & 53 & 28.09 & 93 & 86.49 \\
\hline 14 & 1.96 & 54 & 29.16 & 94 & 88.36 \\
\hline 15 & 2.25 & 55 & 30.25 & 95 & 90.25 \\
\hline 16 & 2.56 & 56 & 31.36 & 96 & 92.16 \\
\hline 17 & 2.89 & 57 & 32.49 & 97 & 94.09 \\
\hline 18 & 3.24 & 58 & 33.64 & 98 & 96.04 \\
\hline 19 & 3.61 & 59 & 34.81 & 99 & 98.01 \\
\hline 20 & 4.00 & 60 & 36.00 & 100 & 100.00 \\
\hline 21 & 4.41 & 61 & 37.21 & 101 & 102.01 \\
\hline 22 & 4.84 & 62 & 38.44 & 102 & 104.04 \\
\hline 23 & 5.29 & 63 & 39.69 & 103 & 106.09 \\
\hline 24 & 5.76 & 64 & 40.96 & 104 & 108.16 \\
\hline 25 & 6.25 & 65 & 42.25 & 105 & 110.25 \\
\hline 26 & 6.76 & 66 & 43.56 & 106 & 112.36 \\
\hline 27 & 7.29 & 67 & 44.89 & 107 & 114.49 \\
\hline 28 & 7.84 & 68 & 46.24 & 108 & 116.64 \\
\hline 29 & 8.41 & 69 & 47.61 & 109 & 118.81 \\
\hline 30 & 9.00 & 70 & 49.00 & 110 & 121.00 \\
\hline 31 & 9.61 & 71 & 50.41 & 111 & 123.21 \\
\hline 32 & 10.24 & 72 & 51.84 & 112 & 125.44 \\
\hline 33 & 10.89 & 73 & 53.29 & 113 & 127.69 \\
\hline 34 & 11.56 & 74 & 54.76 & 114 & 129.96 \\
\hline 35 & 12.25 & 75 & 56.25 & 115 & 132.25 \\
\hline 36 & 12.96 & 76 & 57.76 & 116 & 134.56 \\
\hline 37 & 13.69 & 77 & 59.29 & 117 & 136.89 \\
\hline 38 & 14.44 & 78 & 60.84 & 118 & 139.24 \\
\hline 39 & 15.21 & 79 & 62.41 & 119 & 141.61 \\
\hline 40 & 16.00 & 80 & 64.00 & 120 & 144.00 \\
\hline
\end{tabular}

